About half of the book is devoted to accounts of cases, and includes descriptions by patients of their experiences whilst undergoing treatment.

Discussing the etiology of morphinism the author states that over $50 \%$ of his cases owed their addiction to accidental causes, about $25 \%$ showed definite psychological abnormality, and in $15 \%$ there was a general failure of adaptation to life. These figures are at variance with the experience of others and of our own, which gives as the largest group those who have a constitutional inadequacy of adjustment.

Incidentally it may seem strange to some that a book on the treatment of morphinism should include no chapter on psychological treatment, believing as they do that at least three months of psychotherapy is required after the withdrawal of the drug. Dr. Scott is chiefly concerned with the reduction of pain during the actual withdrawal and thinks that by this means the patient will be more accessible to psychotherapeutic help. The average length of stay in the nursing home was four weeks, but eight cases were able to leave after three weeks or less.

This little book is of convenient size, attractively bound, and should prove of considerable assistance to anyone embarking on the treatment of these difficult cases.

\section{A TEXTBOOK OF PHYSIOLOGY.}

\section{By H. E. Roof, M.D., D.Sc., M.R.C.S., L.R.C.P. Second Edition. Edward Arnold \& Co. 1936. Price 21/-.}

The author of this well-known textbook of physiology has presented an account of physiology which is based on adequate experimental data. The presentation of the subject has been carefully considered and the outcome is a division of the book into four parts. The author leads the student from the known to the unknown, presenting to him the subjects with which he is familiar in the first place and then their application to problems in the body. For example, the mechanics of the heart are considered before the regulation of the organ.

The first section of the book deals with the mechanical aspects of the subject. The various mechanical processes that occur in the body such as the mechanics of respiration, of the circulation, and the heat and electrical changes in muscle, are considered in detail.

Having gained a certain amount of mechanical knowledge a study is made of the means by which these mechanical processes are produced. Thus the second section is concerned with the chemical aspects of physiology.

The third section is devoted to the study of the regulating mechanisms of the body and the final section is concerned with the maintenance of the individual and reproduction of the species.

The author is to be congratulated on the presentation of the subject in such a helpful manner. The book is recommended to those who require an up-to-date knowledge of physiology.

\section{THE HISTORY OF THE ACUTE EXANTHEMATA.}

By J. D. Rolleston, M.A., M.D., F.R.C.P., F.S.A. William Heinemann (Medical Books) Ltd. 1937. Price 7s. 6d.

It is indeed fortunate that it is a condition of the Fitzpatrick Lectureship that the lectures must be published in book form, otherwise we might have been deprived of Dr. Rolleston's most erudite and interesting monograph. No man of course is more qualified than Dr. Rolleston to undertake the unravelling of the history of the exanthemata as he has spent practically his whole active life in their study and treatment. It is without question because of this very personal knowledge of the field that he has produced such a comprehensive and authoritative presentation of the subject.

The diseases which are considered are small pox, chicken pox, scarlet fever, measles and German measles. Each disease is traced from its earliest recorded mention up to the present day, and although it is not to be wondered at that only very slowly did their differentiation from one another come about it is remarkable to see how confusion continued until very recent times. In the case of small pox and chicken pox this confusion is perhaps not so unexpected, since even very recently chicken pox has had to be made a notifiable disease because of the mistakes in diagnosis which were apt to arise. It is, however, with astonishment that one reads 